\title{
GREEN SYNTHESIS OF SUPERPARAMAGNETIC IRON OXIDE NANOPARTICLE FROM FICUS CARICA FRUIT EXTRACT, CHARACTERIZATION STUDIES AND ITS APPLICATION ON DYE DEGRADATION STUDIES
}

\author{
THARUNYA P ${ }^{1}$, SUBHA V ${ }^{1}$, KIRUBANANDAN $S^{1 *}$, SANDHAYA $S^{2}$, RENGANATHAN $\mathbf{S}^{1}$ \\ Centre for Biotechnology, Anna University, Chennai, Tamil Nadu, India. ${ }^{2}$ Department of Biotechnology, VIT University, Vellore, Tamil Nadu, \\ India. Email: skirubanandan80@gmail.com
}

Received: 05 October 2016, Revised and Accepted: 22 December 2016

\begin{abstract}
Objective: The synthesis of nanoparticles (NPs) has become a matter of great interest in recent times due to their various advantageous properties and applications in a variety of fields. Metal NPs are being increasingly used in many sectors, and there is growing interest in the biological and environmental safety of their production.
\end{abstract}

Methods: In this study, iron oxide NPs $\left(\mathrm{Fe}_{3} \mathrm{O}_{4}-\mathrm{NPs}\right)$ were synthesized from fruits of Ficus carica using a rapid, single step and completely green biosynthetic method by reduction of ferrous sulfate solution with $\mathrm{F}$. carica ethanolic extract. The prepared $\mathrm{Fe}_{3} \mathrm{O}_{4}$-NPs were investigated by X-ray diffraction, Fourier transform infrared spectroscopy, and ultraviolet-visible spectroscopy.

Results: The report emphasizes the effect of superparamagnetic $\mathrm{Fe}_{3} \mathrm{O}_{4}$-NPs on the degradation rate of hazardous dyes acid blue.

Conclusion: To conclude, $\mathrm{Fe}_{3} \mathrm{O}_{4}$-NPs were prepared from fruits of $\mathrm{F}$ c carica using a rapid, single step and completely green biosynthetic method by reduction of ferrous sulfate solution with $F$. carica ethanolic extract.

Keywords: Ficus carica, Ethanolic extract, Reduction, Ferrous sulfate, Superparamagnetic iron oxide nano particles, Dye degradation.

(c) 2017 The Authors. Published by Innovare Academic Sciences Pvt Ltd. This is an open access article under the CC BY license (http://creativecommons. org/licenses/by/4. 0/) DOI: http://dx.doi.org/10.22159/ajpcr.2017.v10i3.15538

\section{INTRODUCTION}

Nanotechnology is a multidisciplinary branch of science that encompasses numerous fields of science and technology, including biomedicine, pharmaceutics, environmental science, and others [1]. The use of nanoparticle [NP] materials offers advantages due to their unique size and physicochemical properties. NPs are clusters of atoms in the size range of 1-100 $\mathrm{nm}$. The control of the monodisperse size of NP is very important because the properties of the nanocrystals strongly depend on the dimension of the NPs. One of the most commonly-used nanoscale materials is magnetic NPs (MNPs): A type of core/shell NP structure that consists of a magnetic core encapsulated in an organic or a polymeric coating. Without a coating, MNPs have hydrophobic surfaces with large surface-to-volume ratios and a propensity to agglomerate [2]. Iron oxide $\mathrm{NPs}\left(\mathrm{Fe}_{3} \mathrm{O}_{4}\right.$-NPs $)$ have attracted intensive research interest because of their important applications in cancer therapy, drug delivery, magnetic resonance imaging (MRI), and wastewater treatment [3]. Superparamagnetic $\mathrm{Fe}_{3} \mathrm{O}_{4}$-NPs with appropriate surface chemistry can be used for numerous in vivo applications, such as MRI contrast enhancement, tissue repair, and immunoassay, detoxification of biological fluids, hyperthermia, drug delivery, and cell separation [4]. The biosynthesis of $\mathrm{Fe}_{3} \mathrm{O}_{4}$-NPs of different sizes and shapes has been reported using bacteria [5,6] and plant extract [7]. The stability of iron NPs against aggregation can be improved by imparting electrostatic repulsion, applying organic surfactants, or through the use of capping agents [8]. In recent times, sources of dye contamination have expanded from textile industries to food, paper, printing, cosmetic, and pharmaceutical companies [9]. When these dyes are not treated properly, they get accumulated in the environment and become a threat to the ecosystem. These non-treated dyes are potentially carcinogenic, mutagenic and genotoxic, example of such dyes include Acid Red 26, Direct Blue 6, Direct Black 38, etc. Abatement of dyes is a required part of wastewater treatment. Nanotechnology has been extended to the wastewater treatments in the recent years. Due to high surface area silver NPs exhibits an enhanced reactivity $[10,11]$.

Ficus carica is known to contain polyphenols and flavonoids that act both as a reducing agent and a capping agent. Its fruit, root, and leaves are used in traditional medicine to treat various ailments such as gastrointestinal (colic, indigestion, loss of appetite, and diarrhea), respiratory (sore throats, coughs, and bronchial problems), and cardiovascular disorders and as anti-inflammatory and antispasmodic remedy.

A wide variety of methods have been reported in for the synthesis of $\mathrm{Fe}_{3} \mathrm{O}_{4}$ NPs such as microemulsion technique [12], electrochemical route [13], hydrothermal process [14], sonochemical method [15], and co-precipitation method [16]. Nowadays, synthesis of $\mathrm{Fe}_{3} \mathrm{O}_{4}$-NPs using phytochemicals has attracted much attention due to their simplicity, environmental benignity, and low cost.

Dyes are a major class of synthetic organic compounds released by many industries such as paper, plastic, leather, food, cosmetic, textile, and pharmaceutical industries $[17,18]$. The synthesis and applicability of the $\mathrm{Fe}_{3} \mathrm{O}_{4}$-NPs in the effective removal of acid blue have been reported. The main objective of this study is to test the applicability of $\mathrm{Fe}_{3} \mathrm{O}_{4} \mathrm{NPs}$ as a catalyst in the removal of acid blue dye. Photocatalytic degradation of acid blue was conducted using $\mathrm{Fe}_{3} \mathrm{O}_{4} \mathrm{NP}$ as a catalyst in the presence of sunlight.

\section{METHODS}

\section{Sample collection}

Fig fruits were collected from Anna University, ACT Campus, Chennai, Tamil Nadu, India. 
Preparation of ethanolic extract

Fig fruits were shade dried and grounded well. Ethanol (70\%) was used as hydro alcoholic solution for socking. $15 \mathrm{~g}$ of grounded $F$. carica fruit was socked in $200 \mathrm{ml}$ of $70 \%$ ethanol in a glass beaker for a day. Beaker was sealed with aluminum foil and kept in magnetic stirrer. For coarse filtration, soaked material was filtered several times using filter paper. This coarse filtrate was then filtered through a Whatman filter paper. Using hot air oven, the above filtrate was evaporated at $50^{\circ} \mathrm{C}$ under reduced pressure until the concentrate was reduced to $1 / 3^{\text {rd }}$ of the initial volume. Dark brown colored extract with residues was obtained. The extract, which obtained was then again filtered to remove residues, final extract obtained was dark brown in color and it was stored in refrigerator.

\section{Preparation of $\mathrm{Fe}_{3} \mathrm{O}_{4}-\mathrm{NPs}$}

In a typical reaction procedure, $20 \mathrm{ml}$ of $F$. carica ethanolic extract was added to $270 \mathrm{mg}$ of $\mathrm{FeSO}_{4}$ and $\mathrm{pH}$ is adjusted to 9, using $0.1 \mathrm{M} \mathrm{NaOH}$ solution, then the solution was placed under vigorous magnetic stirring for $4 \mathrm{hrs}$ at $80^{\circ} \mathrm{C}$. During this process, the color of the reaction solution changed from yellowish translucent to a brown color, indicating the formation of $\mathrm{Fe}_{3} \mathrm{O}_{4} \mathrm{NPs}$. The resulting product, iron NP was centrifuged at $7000 \mathrm{rpm}$ for 15-20 minutes and washed several times with 1:1 mixtures of distilled water, and absolute methanol. The purified NP powder was dried at $90^{\circ} \mathrm{C}$ for $16 \mathrm{hrs}$ and stored in an airtight bottle for further characterization by UV, scanning electron microscope, Fourier transform infrared spectroscopy (FTIR), X-ray diffractometer (XRD), and vibrating sample magnetometer.

\section{Procedure for dye degradation}

To $10 \mathrm{ml}$ of dye solution, $\mathrm{Fe}_{3} \mathrm{O}_{4}$-NPs were added and the suspension was subjected to irradiation. Experiments were carried out under sun light. The aqueous suspension was magnetically stirred throughout the experiment. At different time intervals, aliquot was taken out, and the absorption spectra were recorded and rate of decolorization was observed in terms of change in intensity at $\lambda_{\max }$ of the dyes. The decolorization efficiency $\%$ has been calculated as:

Efficiency $\%=\mathrm{C}_{0}-\mathrm{C} / \mathrm{C}_{0} \times 100$

Where $\mathrm{Co}=$ Initial concentration of dye and $\mathrm{C}=$ Concentration of dye after photo irradiation.

\section{RESULTS AND DISCUSSION}

\section{UV-VIS spectroscopy}

The strong interaction of metal NPs with light results in the collective oscillation of the conduction electrons on the metal surface, known as a surface plasmon resonance (SPR). The SPR results in unusually strong scattering and absorption properties. Due to the unique optical properties of $\mathrm{Fe}_{3} \mathrm{O}_{4}$-NPs, a great deal of information about the physical state can be obtained by analyzing the spectra. As the diameter increases, the peak plasmon resonance shifts to longer wavelengths and broadens. Ultraviolet-visible (UV-VIS) spectrum of $\mathrm{Fe}_{3} \mathrm{O}_{4}$-NPs is shown in the Fig. 1 . Here, the sharp peak at $283 \mathrm{~nm}$ indicates the presence of $\mathrm{Fe}_{3} \mathrm{O}_{4}$-NPs. Parallel results were observed by Awwad and Salem [19]. Phytochemicals in the F carica fruit extract was shown to reduce the $\mathrm{Fe}_{3} \mathrm{O}_{4}$-NPs by the indication of suitable SPR with high band intensities and peaks under visible spectrum [20].

\section{FTIR spectroscopy}

FTIR analysis was performed to identify the biomolecules responsible for the reduction of $\mathrm{Fe}_{3} \mathrm{O}_{4}$-NPs present in the fruit extract of F. carica. Fig. 2 shows the FTIR spectrum of the fruit extract. The strong broad peak at $3431 / \mathrm{cm}$ is due to the stretching vibrations of $\mathrm{OH}$ group attributed to water which is present in the fruit extract. The peak at $3009 / \mathrm{cm}$ is assigned to the dimer $\mathrm{OH}$ group in a carboxylic acid. The peak at $2925 / \mathrm{cm}$ is assigned to the asymmetric stretching vibrations of $\mathrm{CH}$ in alkanes. The peak

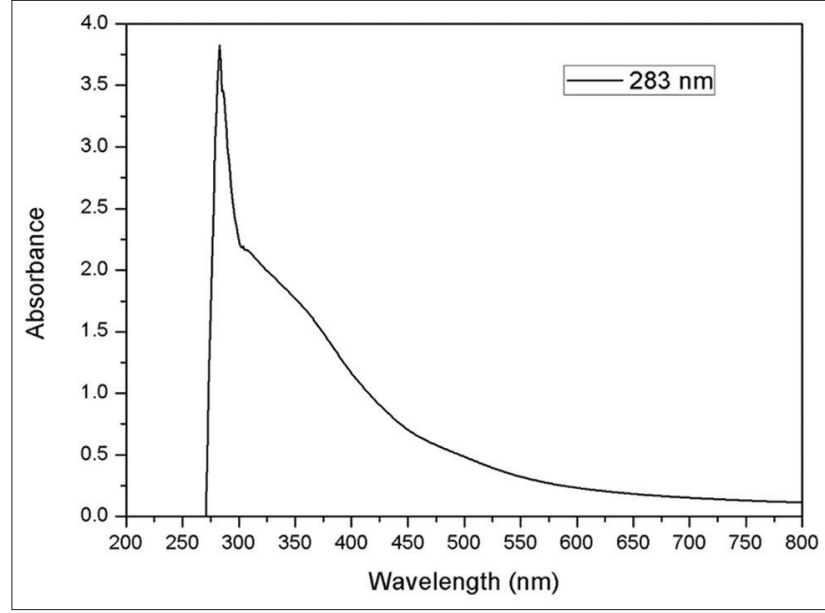

Fig. 1: Ultraviolet-visible absorption spectrum of Iron oxide nanoparticle

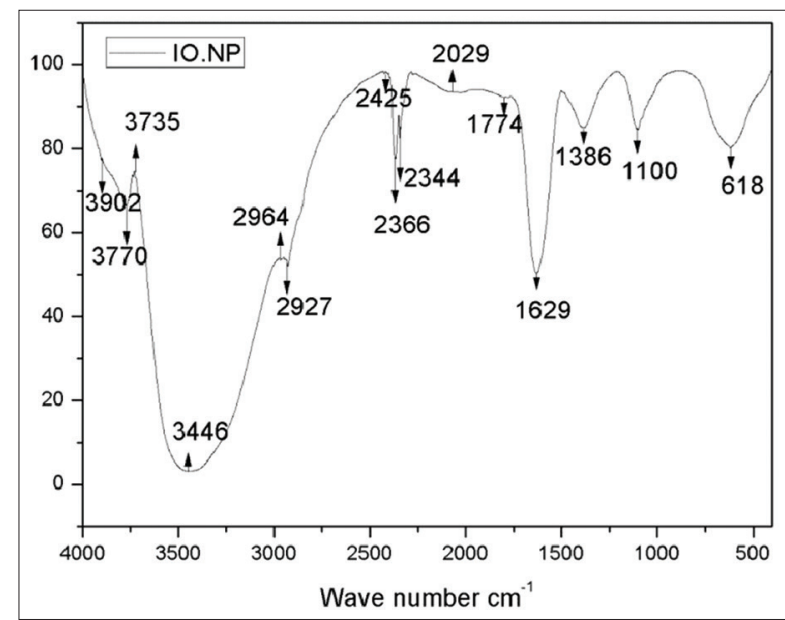

Fig. 2: Fourier transform infrared spectroscopy spectrum of Iron oxide nanoparticle

at $2854 / \mathrm{cm}$ is due to the $\mathrm{C}-\mathrm{H}$ stretch derived from aromatic rings that are present in the extract. The peak at $2367 / \mathrm{cm}$ and $2344 / \mathrm{cm}$ is due to the $\mathrm{P}-\mathrm{H}$ phosphine. The peak at $1721 / \mathrm{cm}$ is assigned for $\mathrm{C}=0$ stretching in aldehydes. The band at $1436 / \mathrm{cm}$ is due to $\mathrm{C}-\mathrm{C}$ ring stretching vibration in Aromatic. The strong peak at $1245 / \mathrm{cm}$ is due to the stretching vibration of $\mathrm{C}=\mathrm{C}$ bond in the alkenes ring. The peak at $1158 / \mathrm{cm}$ is due to C-O stretch. The peak at $1158 / \mathrm{cm}$ is assigned to $\mathrm{C}-\mathrm{F}$ stretch in carboxylic acid, ester. The peak at $1158 / \mathrm{cm}$ is due to $\mathrm{C}-\mathrm{H}$ out of plane (Bending moles). From the FTIR data, it is clear that the bioactive molecules present in the leaves extract of $F$. carica interacted with the synthesized $\mathrm{Fe}_{3} \mathrm{O}_{4}$ NPs.

\section{XRD}

The typical powder XRD pattern of the prepared nanoparticles is shown in Fig. 3. XRD analysis can give you the idea of crystallinity, purity, and size of your synthesized metal NPs. Data were taken for the $2 \theta$ range of $10^{\circ}-70^{\circ}$. The peaks at $31.84^{\circ}, 35.88^{\circ}, 45.56^{\circ}$, and $56.88^{\circ}$ are assigned

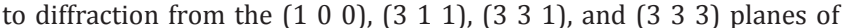
face-centered cubic crystal. The observed peaks were compared with the standard powder diffraction card of (JCPDS File No. 87-0720), and the results are in agreement with the standard XRD pattern of $\mathrm{Fe}_{3} \mathrm{O}_{4}$.

\section{Particle size calculation}

From this study, considering the peak at degree, average particle size has been estimated using Debye-Scherrer formula $[13,15]$.

$\mathrm{D}=0.9 \lambda \beta \operatorname{Cos} \theta$ 


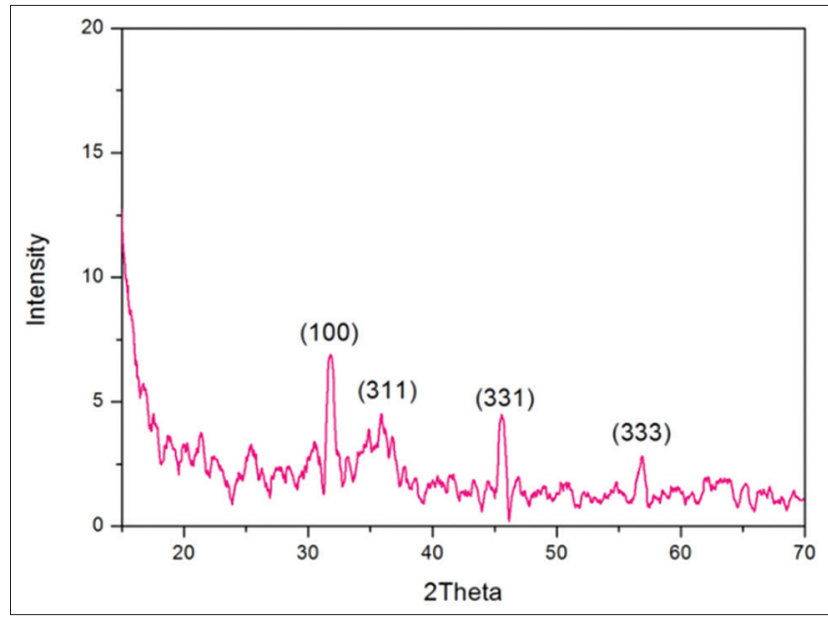

Fig. 3: X-ray diffractometer pattern of Iron oxide nanoparticle

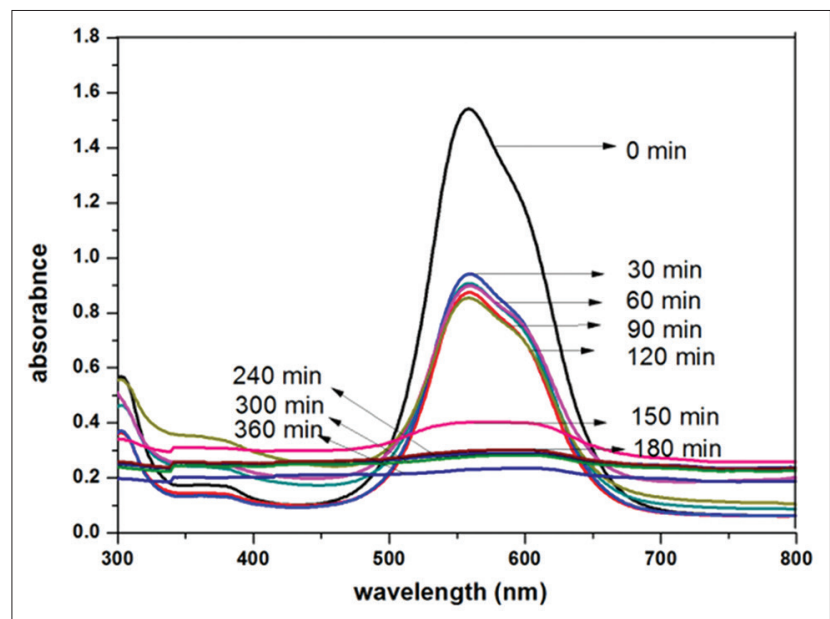

Fig. 4: Variation of dye concentration with time reduction in ultraviolet-visible absorption peaks with time

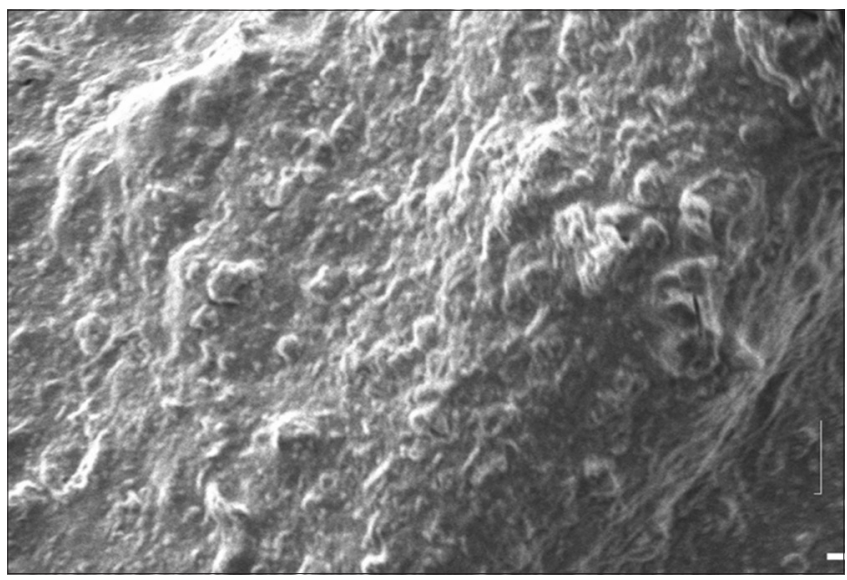

Fig. 5: Iron nanoparticles

Where " $\lambda$ " is wave length of X-ray $(0.1541 \mathrm{~nm})$, " $\beta$ " is full width at half maximum, " $\theta$ " is the diffraction angle, and " $D$ " is particle diameter size.

$$
\text { i. } 2 \theta=31.84
$$

Catalysis occurs only on the surface of metals, and hence increasing the available surface area of the NP will greatly enhance the effectiveness of the catalyst [21]. Decreasing the particle size will increase the catalytic activity, but there is a critical size below which proves that further decreases will hinder the catalytic activity [22]. Metal NPs help in the electron transmits from donor to the acceptor. NPs possess a large surface area which acts as a substrate for the electron transfer reaction. Just before the electron transfer reaction, both of the reactants are adsorbed on the metal surface. Subsequently, the reactant gains an electron and is reduced (Figs. 4 and 5).

\section{CONCLUSION}

To conclude, $\mathrm{Fe}_{3} \mathrm{O}_{4}$-NPs were prepared from fruits of $F$. carica using a rapid, single step, and completely green biosynthetic method by reduction of ferrous sulfate solution with $F$. carica ethanolic extract. The prepared $\mathrm{Fe}_{3} \mathrm{O}_{4}$-NPs were characterized by X-ray diffraction, Fourier transform infrared spectroscopy, and UV-VIS spectrophotometer. The preliminary work confirms the effect of superparamagnetic $\mathrm{Fe}_{3} \mathrm{O}_{4}$-NPs on the degradation rate of hazardous dyes acid blue.

\section{REFERENCES}

1. Chatterjee K, Sarkar S, Jagajjanani Rao K, Paria S. Core/shell nanoparticles in biomedical applications. Adv Colloid Interface Sci 2014;209:8-39.

2. Lu AH, Salabas EL, Schüth F. Magnetic nanoparticles: Synthesis, protection, functionalization, and application. Angew Chem Int Ed Engl 2007;46(8):1222-44.

3. Mody VV, Siwale R, Singh A, Mody HR. Introduction to metallic nanoparticles. J Pharm Bioallied Sci 2010;2(4):282-9.

4. Gupta AK, Gupta M. Synthesis and surface engineering of iron oxide nanoparticles for biomedical applications. Biomaterials 2005;26(18):3995-4021.

5. Yeary LW, Ji WM, Love LJ, Thompson JR, Rawn CJ, Phelps TJ. Magnetic properties of biosynthesized magnetitenanoparticles. Magn IEEE Trans 2005;41:4384-9.

6. Roh Y, Vali H, Phelps TJ, Moon JW. Extracellular synthesis of magnetite and metal-substituted magnetite nanoparticles. J Nanosci Nanotechnol 2006;6(11):3517-20.

7. Senthil M, Ramesh C. Biogenic synthesis of $\mathrm{Fe}_{3} \mathrm{O}_{4}$ nanoparticles using Tridax procumbens leaf extract and its antibacterial activity on Pseudomonas aeruginosa. Digest J Nanomater Bio Struct 2012; 7:1655-60.

8. Manikandan N, Kuzhali SS, Kumuthakalavalli R. Biodegradation of textile dye by using achromobacterxylosoxidans GRIRKNM11 isolated from dye polluted site, Journal of Environ Anal Toxicol 2012;2(160):2

9. Sun YP, Li XQ, Zhang WX, Wang HP. A method for the preparation of stable dispersion of zero-valent iron nanoparticles. Colloids Surf A 2008;308:60-6.

10. Kang SF, Liao CH, Po ST. Decolorization of textile wastewater by photo-fenton oxidation technology. Chemosphere 2000;41(8):1287-94.

11. Deng Y, Wang L, Yang W, Fu S, Elaissari A. Preparation of magnetic polymeric particles via inverse microemulsion polymerization process. J Magn Magn Mater 2003;257:69-78.

12. Franger S, Berthet P, Berthon J. Electrochemical synthesis of $\mathrm{Fe}_{3} \mathrm{O}_{4}$ nanoparticles in alkaline aqueous solutions containing complexing agents. J Solid State Electrochem 2004;8:218-23.

13. Hua J, Yong, HQ. Controlled synthesis and magnetic properties of $\mathrm{Fe} 3 \mathrm{O}_{4}$ walnut spherical particles and octahedral microcrystals. Sci Chin Technol Sci 2008;5:1911-20.

14. Islam N, Phong LV, Jeong JR, Kim CG. A facile route to sonochemical synthesis of magnetic iron oxide $\left(\mathrm{Fe}_{3} \mathrm{O}_{4}\right)$ nanoparticles. J Thin Solid Films 2011;519:8277-9.

15. Wu W, He Q, Jiang C. Magnetic iron oxide nanoparticles: Synthesis and surface functionalization strategies. Nanoscale Res Lett 2008:3:397-415.

16. Kulkarni SV, Blackwell CD, Blackard AL, Stackhocese CW, Alexander MW. Textile Dyes and Dyeing Equipment, Classification, Properties and Environmental Aspects. NC (EPA-600/2-85/010). Research Triangle Park, NC: US Environmental Protection Agency; 1985.

17. Zollinger H. Color Chemistry: Synthesis, Properties and Applications of Organic and Pigments. New York: Wiley-VCH; 1987. p. 543-66.

18. Saravanan M, Prakash NK, Arasu M, Vijayakumar B, Vincent S. Enhanced antibacterial activity of iron oxide magnetic nanoparticles 
treated with Argemone mexicana leaf extract: An in vitro study. Mater Res Bull 2013;48:3323-7.

19. Awwad AM, Salem NM. A green and facile approach for synthesis of magnetite nanoparticles. J Nanosci Nanotechnol 2012;2(6):208-13.

20. Guo L, Liu G, Hong RY, Li HZ. Preparation and characterization of chitosan poly(acrylic acid) magnetic microspheres. Mar Drugs 2010;8:2212-22.
21. Frelink T, Visscher W, Veen J. Particle size effect of carbon supported platinum catalysts for the electro oxidation of methanol. J Electroanal Chem 1995;382:65-72.

22. Falicov LM, Somorjai GA. Correlation between catalytic activity and bonding and coordination number of atoms and molecules on transition metal surfaces: Theory and experimental evidence. Proc Natl Acad Sci India Sect B Biol Sci 1985; 82: 2207-11 